\title{
Agresión sexual
}

\section{Sexual assault}

\section{S. Lapeña ${ }^{1}$, A. Gaztambide ${ }^{2}$, I. Huarte ${ }^{2}$}

\section{RESUMEN}

Los delitos contra la agresión sexual constituyen uno de los temas de mayor interés en el momento actual y en diferentes campos sociales (judicial, médico, policial, criminológico...). La importancia radica en la frecuencia de los mismos y las repercusiones legales, físicas y psicológicas que conllevan.

Debido a ello es importante tener clara la pauta de actuación en urgencias frente a tales delitos, siendo minucioso en la realización del informe ginecológico y en la toma de muestras, ofertando profilaxis de enfermedades de transmisión sexual y embarazos no deseados y prestando apoyo psicológico.

Palabras clave. Multidisciplinar. Esfera psicológica. Enfermedades de transmisión sexual. Seguimiento.

\begin{abstract}
Offences involving sexual assault are an issue of the greatest current interest in different social fields (legal, medical, police, criminological...). They are significant due to their frequency and to the legal, physical and psychological repercussions involved.

It is therefore important to clearly understand the pattern of action in Accidents and Emergencies facing such cases. Great detail is required in the gynaecological report and the taking of samples, prophylaxes for sexually transmitted diseases and unwanted pregnancies must be given and psychological support provided.
\end{abstract}

Key words. Multidisciplinarity. Psychological sphere Sexually transmitted diseases. Follow up.
1. Hospital García Orcoyen. Estella. Navarra.

2. Centros de Atención a la Mujer. Servicio Navarro de Salud-Osasunbidea.
Correspondencia:

Sonia Lapeña

Hospital García Orcoyen

C/ Santa Soria, s/n

31200 Estella (Navarra)

E-mail: slapenac@cfnavarra.es 


\section{INTRODUCCIÓN}

Según la reforma del código penal en 1995 desaparecen los términos de violación y estupro y se recogen las siguientes definiciones:

- Agresión es la relación sexual no consentida, que se consigue por medio de violencia, intimidación y con circunstancias agravantes (artículos 178, 179,180).

- Abuso es el ataque a la libertad sexual, no consentida por la víctima, pero sin violencia ni intimidación ${ }^{1}$.

En cuanto a la incidencia no se conoce de forma exacta debido a que sólo el $10-15 \%$ de la víctimas denuncian debido a diferentes motivos: sentimientos de culpa, dependencia económica del agresor, etc.

La inmensa mayoría de las víctimas son de sexo femenino, siendo sólo entre un $7-10 \%$ de las víctimas del sexo masculino. El $30-50 \%$ se producen en el domicilio y con frecuencia por familiares o conocidos. El 30-40\% se producen bajo los efectos del alcohol $^{2}$.

Es un tema importante por su gran frecuencia (debido al aumento real de casos y la concienciación de la denuncia) y por las consecuencias derivadas (lesiones físicas, psíquicas, embarazos no deseados y contagio de enfermedades de transmisión sexual).

\section{ATENCIÓN A LA PACIENTE}

La atención que se debe prestar debe ser multidisciplinar con atención médica, psicológica y legal. El médico forense se dedicará a la obtención de pruebas, confección de informe legal y protección de pruebas para la policía jurídica. El especialista en Ginecología esta obligado a comunicar al Juzgado la sospecha de agresión sexual (si no se ha realizado previamente). El informe ginecológico se limitará a consignar "sospecha de agresión sexual" sin afirmar o negar la existencia de la misma, en una actuación objetiva, descriptiva y sin prejuicios. Se debe informar por escrito con copia archivada, y el informe ginecológico contendrá:

- Declaración de la paciente.

- Observaciones del médico.
- Procedimientos efectuados.

- Nombres de testigos en historia, exploración y entrega de muestras ${ }^{3}$.

\section{ACTUACIÓN MÉDICA}

Los criterios de inclusión de atención en urgencias de agresión sexual ${ }^{4}$ son:

- Agresión reciente (menor de 72 horas).

- Abuso crónico con última agresión hace menos de 72 horas.

- Presencia de síntomas o signos de aparición reciente que hagan sospechar casos de abusos.

- Riesgo de pérdida de pruebas.

- Necesidad de protección urgente a la víctima.

- Necesidad de tratamiento urgente físico o psíquico.

Cuando no se esté ante uno de estos supuestos la agresión debe considerarse como crónica y se podrá remitir para evaluación ginecológica de manera ambulatoria.

La actuación del ginecólogo estará basada en: anamnesis, exploración física, recogida de muestras, tratamiento y seguimiento.

\section{Anamnesis}

- Historia médico quirúrgica: nombre, edad, estado civil. Alergias. Enfermedades e intervenciones quirúrgicas previas. Alcohol, drogas...Estado inmunitario frente al tétanos y de la hepatitis B.

- Historia ginecológica: menarquia, fecha última regla, antecedentes sexuales y reproductivos, método anticonceptivo actual, enfermedades de trasmisión sexual previas.

- Datos de la agresión: quién, cuándo y dónde se produce la agresión; cuál fue la agresión; circunstancias, descripción del agresor; si la víctima experimentó pérdida de conciencia o memoria; última relación sexual consentida, actitud posterior a la agresión (ducha...) $)^{5}$. 


\section{Exploración física}

Siempre que sea posible realizar la exploración en presencia de un forense para evitar exploraciones repetitivas e innecesarias. Es necesario crear un ambiente adecuado para la paciente, explicando de manera clara la actuación a seguir.

\section{Exploración general}

- Toma de constantes.

- Estado de conciencia y nivel emocional.

- Estado de ropas, manchas... (siendo lo más descriptivo posible).

- Contusiones, erosiones, señales de violencia (sobre todo en cara, cavidad oral, cuello, mamas, muñecas, muslos y nalgas). A ser posible con soporte fotográfico (con consentimiento previo de la paciente).

\section{Exploración ginecológica}

- Vulvar: edemas, desgarros, hematomas, lesiones en monte de Venus. Para ver pequeñas lesiones usar azul de toluidina y posteriormente ácido acético (colposcopia).

- Hímen: morfología, elasticidad, consistencia, desgarros (número, situación horaria, profundidad...).

- Ano: inspección del esfínter anal (dilatación, espasmo), fisuras, lesiones...

- Espéculo: el único lubricante permitido es el suero salino fisiológico para valorar vagina, fondos de saco y cérvix.

\section{Recogida de muestras}

Éstas, previa información y autorización de la paciente, deben ir identificadas correctamente y se entregarán al forense o al Juzgado.

\section{Generales}

- Recoger todas las pruebas que observemos (pelos, semen, sangre, fibras textiles...)
- Ropas de la paciente recogidas con guantes.

- Identificar manchas de semen (Lámpara de Wood).

- Rascado de la zona interior de las uñas para recogida de posibles restos de piel.

- Muestras de saliva para DNA (si penetración oral) ${ }^{6}$.

\section{Ginecológicas}

- Peinado de vello púbico para buscar vello del agresor.

- Muestras de exudado vaginal y cervical. Si es escaso, realizar lavado vaginal con $4 \mathrm{ml}$ de suero fisiológico y aspirarlo.

- Muestras anales si sospecha de afectación.

- Hisopo seco para DNA.

- Una muestra vaginal en fresco puede ser examinada para visualizar espermatozoides móviles, vaginosis bacteriana y tricomonas.

\section{Solicitar}

- Despistaje inicial y a las 2 semanas de gonococo, Clamidia y tricomonas.

- Grupo y Rh, tóxicos o estupefacientes (según las circunstancias).

- Prueba de embarazo inicial y a las 6 semanas.

- Serologías de ETS:

- Hepatitis B: inicial y a las 6 semanas.

- Hepatitis C: inicial y a las 6 semanas.

- VIH: inicial, a las 6 semanas y a los 3-6 meses.

- Sífilis: inicial, a las 6 semanas y a los 3-6 meses $^{6}$.

\section{Tratamiento}

Los criterios de ingreso de las víctimas de agresión sexual son ${ }^{4}$ :

- Necesidad de cuidados hospitalarios.

- Tratamiento psicológico urgente.

- Necesidad de exploración bajo anestesia. 
- Necesidad de exploraciones o estudios posteriores.

- Demanda de la paciente.

- Asegurar la protección de la víctima.

El tratamiento a realizar será:

1. Tratamiento quirúrgico, si precisa (heridas, fracturas, desgarros...).

2. Vacuna antitetánica, si existen lesiones y no estaba vacunada.

3. Analgésicos o sedantes, si precisa.

4. Profilaxis de VHB: si no estaba vacunada. Con vacuna (20 $\mathrm{mg}$ IM en deltoides10, 1,6 meses) + inmunoglobulina específica $(0,06 \mathrm{ml} / \mathrm{Kg} \mathrm{IM}$ en glúteo).

5. Contracepción postcoital de emergencia. El riesgo de embarazo después de un episodio de penetración vaginal varía según el momento del ciclo menstrual. La contracepción de emergencia debería ser ofrecida con independencia del día del ciclo menstrual. En las primeras 72 horas:

- levonorgestrel 1,5 mg vía oral dosis única o 0,75 vía oral en dos dosis en total (más efectiva que la Yuzpe).

- Yuzpe: etinil estradiol $100 \mathrm{ng}+\mathrm{le}-$ vonorgestrel $0,5 \mathrm{mg} 2$ comprimidos cada 12 horas dos días vía oral.

Desde las 72 horas hasta 5 días tras la agresión se realizará inserción de DIU hasta 2-3 semanas después de la regla.

6. Según el Center for Disease Control and Prevention (CDC) y otras asociaciones se recomienda la profilaxis empírica de las enfermedades de trasmisión sexual (ETS) debido a que muchas víctimas no cumplen el tratamiento posterior y el tratamiento basado en los resultados de los cultivos puede resultar problemático ${ }^{7}$. El riesgo de ETS es difícil de medir. El riesgo de ETS por Clamidia es de $3-16 \%$, de enfermedad pélvica inflamatoria y vaginosis bacteriana $11 \%$ y de tricomonas de $7 \%$.

- Gonococo: ceftriaxona 125-250 mg intramuscular dosis única.

- Clamidia: azitromicina $1 \mathrm{~g}$ vía oral dosis única o doxiciclina 100 $\mathrm{mg} / 12 \mathrm{~h}$ vía oral 7 días.
- G. vaginalis o tricomonas: metronidazol $2 \mathrm{~g}$ vía oral dosis única.

7. Profilaxis VIH. El tratamiento profiláctico con drogas antivirales es controvertido. El riesgo de VIH después de un episodio de penetración vaginal está estimado en $0,1 \%$ y después de una penetración anal del $2 \%$. Sin embargo, en países con baja tasa de seroprevalencia el riesgo es bajo $^{6}$. Ciertas condiciones de la agresión pueden aumentar el riesgo:

- Agresión en países con mayores tasas de seroprevalencia.

- Múltiples asaltantes.

- Agresión sexual anal.

- Si el agresor o la víctima tienen lesiones traumáticas, sangrado o lesiones genitales.

A pesar del bajo riesgo de trasmisión del VIH y la falta de evidencia del tratamiento antirretroviral, se cree que debería ser ofrecido. Siguiendo el modelo de exposición ocupacional al VIH el tratamiento antirretroviral debería ser iniciado dentro de las 4 horas postagresión y no debería ser prescrito si han transcurrido más de 72 horas. Los regímenes de profilaxis utilizados en la exposición accidental de los trabajadores de la salud son los que deberían ser ofrecidos. Deben suministrarse en el servicio de urgencias: Retrovir + epivir (Combivir $\left.{ }^{\circledR}\right)(1-0-1)+$ LPV/r (Kaletra $\left.{ }^{\circledR}\right) 2$ cada 12 horas durante 3 días. Tras ello se debería de remitir a la paciente a la consulta de enfermedades infecciosas para valorar el riesgobeneficio del tratamiento con antirretrovirales, valorando el riesgo de trasmisión de VIH según las circunstancias de la agresión y la toxicidad del tratamiento de profilaxis de VIH.

8. Tratamiento psicosocial. Las víctimas de agresión sexual requieren un cuidadoso soporte emocional y deben ser puestos a su disposición cuidados psicológicos. Se cifra alrededor de un $30 \%$ de víctimas que sufren síndrome de estrés postraumático.La propia evaluación médica a la hora de la recogida de muestras y exploración en urgencias pueden ser 
vividas como parte de esa pérdida de control de uno mismo, debiendo en todo momento respetar la capacidad de control de la persona, para evitar así en la medida de lo posible, mayores daños psicológicos. En Navarra el Instituto Navarro de la Mujer (INAM), que está coordinado a través del teléfono 112 cuenta con apoyo psicológico las 24 horas, casas de acogida y servicio de asistencia jurídica gratuita permanente ${ }^{8}$.

\section{Seguimiento}

El seguimiento debe ser psicológico y médico. Se deben hacer:

- Serologías: hepatitis B y C (a las 6 semanas), sífilis y VIH (a las 6 semanas y a los 3-6 meses).

- Revacunaciones (del tétanos al mes y al año, de la VHB al mes y a los 6 meses).

- Despistaje a las 2 semanas de gonococo, clamidia, vaginosis bacteriana y tricomonas (si no se realizó profilaxis o si presenta sintomatología).

- Prueba de embarazo a las 6 semanas y si es positiva, ofertar interrupción legal del embarazo.

- Recordar el uso de preservativo para las relaciones sexuales hasta completado los test serológicos.

\section{AGRESIÓN SEXUAL EN PACIENTES PEDIÁTRICAS}

Se pueden encontrar distintos tipos de los cuadros de agresión sexual en menores, que varían en un espectro muy amplio de formas dependiendo de varios factores: edad de la víctima, abuso agudo o crónico, presencia de lesiones físicas o psicológicas, capacidad de verbalización de la pacien- te... En casos de retraso mental puede ser necesario el permiso del Juez de guardia.

Se debe crear un ambiente adecuado, evitando preguntas con excesiva carga de ansiedad y se debe contar con la presencia del forense para la toma de muestras.

La técnica de toma de semen de vagina se realizará sin espéculo con una torunda fina a través de introito vulvar o mediante aspiración-lavado con catéter fino.

Las lesiones físicas más frecuentes en casos agudos son las transecciones himeneales (alrededor del 50\%), siendo poco frecuentes las debidas a causas accidentales. Otras lesiones en casos crónicos son las retracciones himeneales o restos himeneales, siendo altamente sospechosas las dilataciones graduales de la vagina $\mathrm{y}$ alteraciones del esfínter anal ${ }^{4}$.

\section{BIBLIOGRAFÍA}

1. Código Penal. $2^{a}$ ed. 1996. Editorial Cólex 1996.

2. En protocolos asistenciales en Ginecología y Obstetricia de la SEGO (2005).

3. Lombardia Prieto J, Fernández Pérez M. Ginecología y Obstetricia: Manual de consulta rápida. Ed. Panamericana. 2a edición. 2007.

4. Jiménez A, Rustarazo I, Arnedo S. Agresión sexual. Urgencias en ginecología y obstetricia: aproximación a la medicina basada en la evidencia. 2007.

5. De los Reyes S, Lertxundi R, Haya J. Abusos y agresiones sexuales. Manual de salud reproductiva en la adolescencia. Sociedad Española de Contracepción de 2001.

6. CARL K BATS MD. Evaluation and management of sexual assault victims. Official reprint UptoDate October 2008.

7. Sexually Transmited disease treatment. Guidelines 2006. Center for Disease Control and Prevention MMWR Recomm Rep 2006; 55:1.

8. LETE A. Acuerdo interinstitucional para la atención a las mujeres víctimas de maltrato doméstico y/o agresiones sexuales. Protocolo de actuación. Pamplona, Instituto Navarro de la Mujer, 2002. 
